\title{
A MEMS BASED METHOD TO FABRICATE A MICRO PRESSURE SWIRL ATOMIZER AND ITS PERFORMANCE
}

\author{
Dhivyaraja Kumaran ${ }^{1}$, David Gaddes ${ }^{2}$,Eugene Freeman ${ }^{2}$, Srinivas Tadigadapa ${ }^{2,3}$ and Mahesh V. Panchagnula ${ }^{1}$ \\ ${ }^{1}$ Department of Applied Mechanics, Indian Institute of Technology Madras, Tamil Nadu, India \\ ${ }^{2}$ Department of Biomedical Engineering, Pennsylvania State University, University Park, USA \\ ${ }^{3}$ Department of Electrical Engineering, Pennsylvania State University, University Park, USA
}

\section{INTRODUCTION}

Miniaturization of spray nozzle geometry [1] is likely to create the next generation innovations in the development of gas turbine injectors [2]. Several techniques have been explored to fabricate the atomizers in the microscale [3]. Here we use siliconglass wafer bonding and micromachining techniques to realize micro-atomizer arrays [4]. We have used a $\operatorname{SetScan}^{\circledR}$ optical patternator, consisting of six laser sheets and six array camera, to non-invasively characterize the uniformity of the micro-atomizer spray [5] along with high-speed shadow graphic imaging technique using a Photron Fastcam ${ }^{\circledR}$ to measure the spray angle. This study reports a parametric variation of the micro-atomizers to explore the limits of miniaturization while not compromising spray quality. The flow numbers [1] that we have been able to achieve in this study are well below those commercially available at acceptable spray quality. This technology holds promise to reliably manufacture microspray injectors, which could lead a paradigm shift in atomizer technology.

\section{MICRO ATOMIZERS FABRICATION PROCESS}

Figure 1 illustrates top and cross-sectional views of the microspray atomizer chip and the fabrication process used. A 450 $\mu \mathrm{m}$ thick 4 inch, (100) double-side polished silicon wafer was photolithographically patterned with the swirlers pattern. The wafer was then etched using a deep reactive ion etcher (DRIE), creating $100 \mu \mathrm{m}$ deep channels (see Figure. 1(A)). The etched silicon is anodically bonded to a $150 \mu \mathrm{m}$ thick borofloat glass wafer. Thereafter, silicon surface of the bonded wafer was patterned to define the outlet for the spray (see Figure 1(B)) and etched through the remaining thickness of silicon in the patterned region. The bonded stack was next placed into $49 \%$ HF to reduce the thickness of the glass to $\sim 50 \mu \mathrm{m}$. Finally, four supply (inlet) holes were patterned on the glass side. Nickel electrodeposition was performed to create a mask for RIE glass etching. The exposed glass was etched down through the glass thickness to form the inlet orifices (see Figure 1(C)). Figure 1 shows three atomizers, multiple spray configurations. A set of 25 variations of the base design atomizers have been fabricated by varying one parameter at a time.

\section{RESULTS AND DISCUSSION}

All the micro-atomizer spray experiments have been performed at 8 bar supply pressure and the optical patternation measurement plane B'B" is located $5 \mathrm{~mm}$ below from the exit orifice. Device number $\left(D_{N}\right) 2$ has the highest spray angle and also exhibited the most uniform spray among all the design variations. Figure 2 shows the high speed shadow graph image of the spray from $D_{N}-2$. The time averaged spray pattern of $D_{N}-2$ is shown in Figure 3. Figure 4 shows the line-of-sight averaged surface area per unit length of the spray contour in Figure 3, which indicates the degree of hollowness of the spray. The flow rate $(Q)$ and the spray angle (2Ө) are well correlated as seen in Figure 5. Increase in the flow rate increases the spray angle. The flow rate is increased by increasing the number of inlet slots $\left(S_{n}\right)$. The spray angle is increased by decreasing the swirl chamber diameter $\left(D_{s}\right)$ to exit orifice diameter $\left(d_{o}\right)$ ratio as well as slot length $\left(S_{l}\right)$ to slot width
$\left(S_{w}\right)$ ratio. These dependencies are shown in Figure 6. The detailed parametric variations of the atomizers along with the experimentally measured flow and spray angle data are listed in Table 1. Increasing the number of inlet ports increases the swirl velocity inside the swirl chamber, which results in large spray angle. The time averaged spray pattern contour for the various parametric atomizer designs are shown in Table 2. This table qualitatively describes the effect of the various flow parameters on spray uniformity.

\section{WORD COUNT: 600}
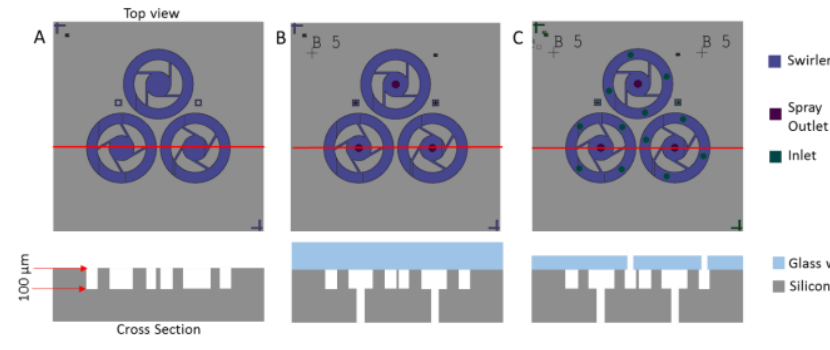

Figure 1: Cross-sectional views of the devices

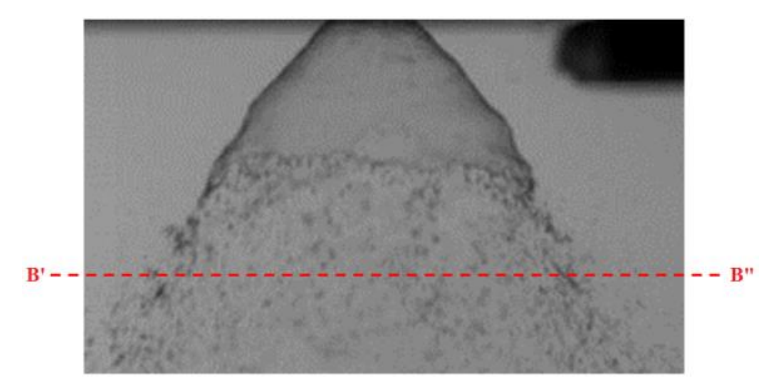

Figure 2: High speed shadow graph image captured at $50 \mathrm{kHz}$ on Device No.2

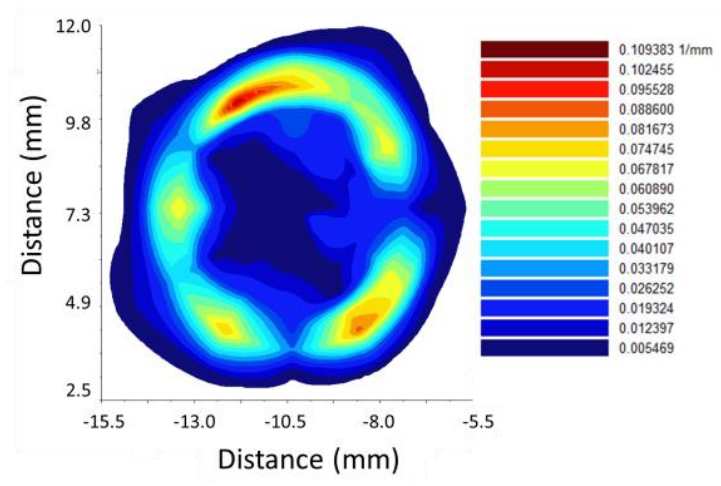

Figure 3: Time averaged spray pattern on $D_{N-2}$ in $B^{\prime}-B^{\prime \prime}$ Plane

Solid-State Sensors, Actuators and Microsystems Workshop Hilton Head Island, South Carolina, June 5-9, 2016 


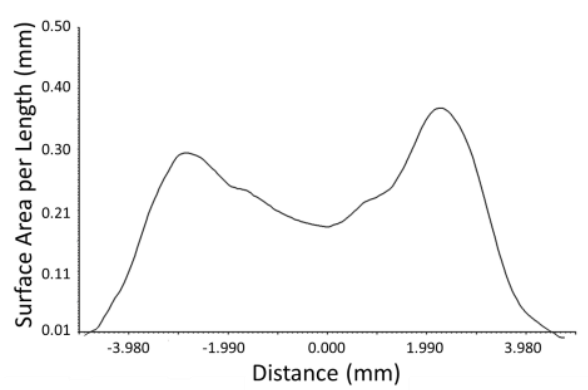

Figure 4: Line-of-sight averaged surface area per unit length showing the hollowness of the spray in $D_{N-2}$ in $B^{\prime}-B^{\prime \prime}$ Plane

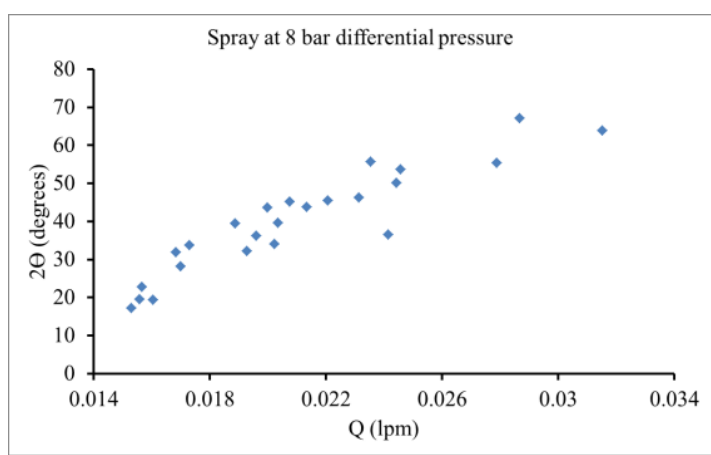

Figure 5: Spray angle (2Ө) and flow rate $(Q)$ measurements.

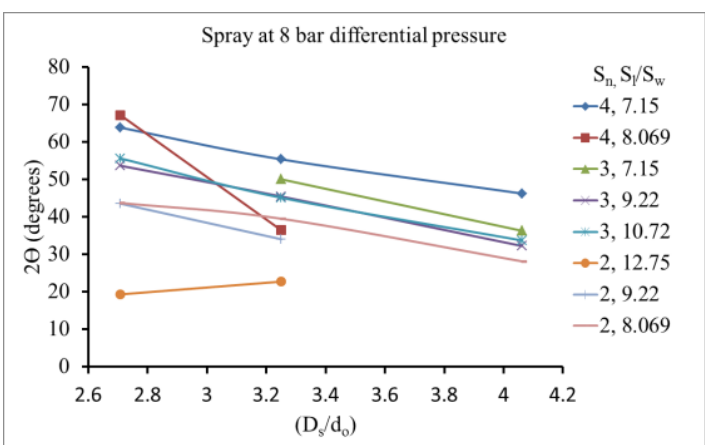

Figure 6: Spray angle (2Ө) measurements with respect to geometric variation

Table 1: Device specifications and experimentally measured data

\begin{tabular}{|c|c|c|c|c|c|}
\hline $\boldsymbol{D}_{\boldsymbol{N}}$ & $\boldsymbol{S}_{\boldsymbol{n}}$ & $\boldsymbol{S}_{\boldsymbol{V}} \boldsymbol{S}_{\boldsymbol{w}}$ & $\boldsymbol{D}_{\boldsymbol{s}} / \boldsymbol{d}_{\boldsymbol{o}}$ & $\boldsymbol{Q}(\mathbf{l p m})$ & $\mathbf{2 \Theta}($ degrees $)$ \\
\hline 1 & 4 & 8.069 & 0.951 & 0.0242 & 36.44 \\
\hline 2 & 4 & 8.069 & 0.792 & 0.0287 & 67.18 \\
\hline 3 & 4 & 7.15 & 1.188 & 0.0231 & 46.22 \\
\hline 4 & 4 & 7.15 & 0.951 & 0.0279 & 55.38 \\
\hline 5 & 4 & 7.15 & 0.792 & 0.0315 & 63.84 \\
\hline 6 & 3 & 12.75 & 1.188 & 0.0168 & 31.83 \\
\hline 7 & 3 & 10.72 & 1.188 & 0.0173 & 33.69 \\
\hline 8 & 3 & 10.72 & 0.951 & 0.0208 & 45.12 \\
\hline 9 & 3 & 10.72 & 0.792 & 0.0235 & 55.61 \\
\hline 10 & 3 & 9.22 & 1.188 & 0.0193 & 32.21 \\
\hline 11 & 3 & 9.22 & 0.951 & 0.0221 & 45.44 \\
\hline 12 & 3 & 9.22 & 0.792 & 0.0246 & 53.67 \\
\hline 13 & 3 & 8.069 & 1.188 & 0.0203 & 39.65 \\
\hline 14 & 3 & 7.15 & 1.188 & 0.0196 & 36.26 \\
\hline 15 & 3 & 7.15 & 0.951 & 0.0244 & 50.04 \\
\hline 16 & 2 & 12.75 & 1.188 & 0.0109 & 0.00 \\
\hline 17 & 2 & 12.75 & 0.951 & 0.0157 & 22.72 \\
\hline 18 & 2 & 12.75 & 0.792 & 0.0161 & 19.29 \\
\hline
\end{tabular}

\begin{tabular}{|c|c|c|c|c|c|}
\hline 19 & 2 & 10.72 & 1.188 & 0.0153 & 17.20 \\
\hline 20 & 2 & 9.22 & 0.951 & 0.0202 & 34.03 \\
\hline 21 & 2 & 9.22 & 0.792 & 0.0200 & 43.54 \\
\hline 22 & 2 & 8.069 & 1.188 & 0.0170 & 28.13 \\
\hline 23 & 2 & 8.069 & 0.951 & 0.0189 & 39.51 \\
\hline 24 & 2 & 8.069 & 0.792 & 0.0214 & 43.72 \\
\hline 25 & 2 & 7.15 & 1.188 & 0.0156 & 19.51 \\
\hline
\end{tabular}

Table 2: Devices and their time averaged spray pattern contours. The following key observations can be made: (i) $S_{n}-4$ sprays are generally more uniform than $S_{n-3} \& S_{n}-2$ sprays. (ii) In $S_{n-2}$ devices, the spray is not fully open as it remains in the onion formation stage. (iii) The hot spots in the $D_{N-2}$ spray shows some memory of the inlet slots but is the best atomizer design of the lot tested in terms of pattern uniformity (iv) Hot spots in $D_{N^{-}} 7$ is not a result of inlet slot memory; it is a result of the reunion of the dispersed liquid sheet due to the atomizer's inability to form a fully developed hollow cone.(v) Some contour plots have more number of hot spots than inlets (for example, $D_{N}-14$ and $D_{N-8}$ ). This is due to the high temporal spray angle fluctuation.

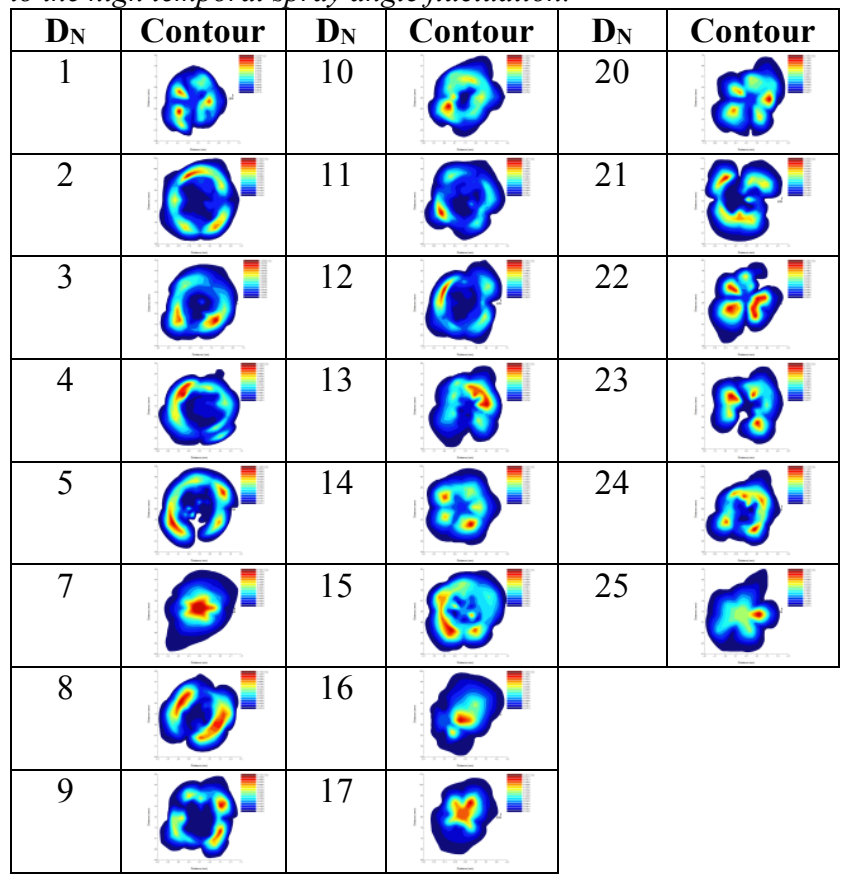

\section{REFERENCES}

[1] A.H. Lefebvre, "Atomization and Sprays", Hemisphere Publishing Corporation, New York, (1989)

[2] H.C. Simmons and R.J. Harvey, "Spray Nozzle and Method of Manufacturing Same, Parker-Hannifin Corporation", US Patent- 5,435,884 (1995)

[3] A. Singh, M. Mehregany, S.M. Phillips, R.J. Harvey and M. Benjamin, "Micromachined Silicon Fuel Atomizers for Gas Turbine Engines", Atomization and Sprays, vol.8, pp.405418, (1998)

[4] K. Dhivyaraja, D. Gaddes, M.V. Panchagnula and S. Tadigadapa, "Geometrical Scaling Effects on The Properties of Pressure Swirl Microsprays", $13^{\text {th }}$ Triennial International Conference on Liquid Atomization and Spray Systems, Tainan, Taiwan, August 23-27, (2004), A4-2-192.

[5] Jongmook Lim, Yudaya Sivathanu, Vinoo Narayanan and Seungmin Chang, "Optical Patternation of A Water Spray Using Statistical Extinction Tomography ", Atomization and Sprays, vol.13, pp.27-43, (2003) 